\title{
Contagem de células somáticas em leite cru refrigerado de produtores individuais através de métodos rápidos
}

Somatic cell counts in refrigerated raw millk from individual producers through rapid methods Recuento de células somáticas en leche cruda refrigerada de productores individuales utilizando métodos rápidos

Recebido: 17/04/2021 | Revisado: 23/04/2021 | Aceito: 06/05/2021 | Publicado: 19/05/2021

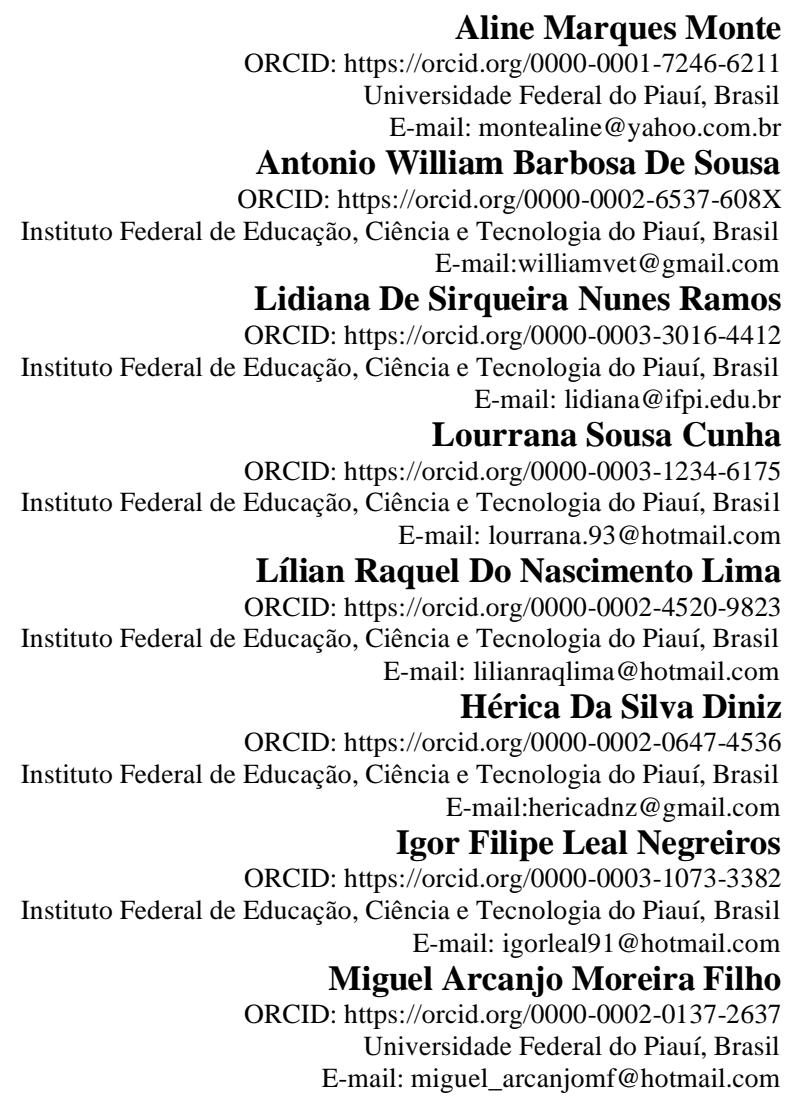

\section{Resumo}

Objetivos: Avaliou-se o efeito de métodos rápidos sobre a contagem de células somáticas (CCS) em leite cru fornecido por produtores individuais. Foram coletadas 140 amostras de leite de vacas leiteiras oriundas de 20 produtores localizados no estado do Piauí. Adotou-se o delineamento em blocos ao acaso, com dois tratamentos T1 e T2 e sete repetições analisadas em duplicata. A média dos tratamentos (T1) Somaticell e (T2) Ekomilk scan foram respectivamente 432,56 e 229,22. Os Kits somatcell e ekomilk scan utilizados neste trabalho mostraram-se eficientes para contagem de CCS no leite cru refrigerado de produtor individual.

Palavras-chave: Mastite bovina; Qualidade do leite; CCS.

\section{Abstract}

Objectives: The evaluated the effect of rapid methods for somatic cell count (SCC) in milk. We collected 140 milk samples from dairy cows originating from 20 producers located in the state of Piauí. The design was adopted in a randomized block design with two treatments $\mathrm{T} 1$ and $\mathrm{T} 2$ and seven replicates analyzed in duplicate. The average of the treatments (T1) somaticell and (T2) ekomilk scan were respectively 432.56 and 229.22. Kits somatcell and ekomilk scan used in this study were effective for CCS count in refrigerated raw milk from individual producers.

Keywords: Bovine mastitis; Milk quality; CCS. 


\section{Resumen}

Objetivos: Evaluaron el efecto de los métodos rápidos para el recuento de células somáticas (CCE) en la leche. Recolectamos 140 muestras de leche de vacas lecheras provenientes de 20 productores ubicados en el estado de Piauí. El diseño fue adoptado en un diseño de bloques al azar con dos tratamientos T1 y T2 y siete repeticiones analizadas por duplicado. El promedio de los tratamientos (T1) somaticell y (T2) ekomilk scan fueron respectivamente 432.56 y 229.22. Los kits somatcell y ekomilk scan utilizados en este estudio fueron efectivos para el recuento de CCS en leche cruda refrigerada de productores individuales.

Palabras clave: Mastitis bovina; Calidad de la leche; CCS.

\section{Introdução}

O leite é um dos alimentos de maior importância para a sociedade humana (Durr, 2004). É um produto delicado e altamente perecível, tendo suas características físicas, químicas e biológicas facilmente alteradas pela ação de microorganismos e pela manipulação a que é submetido.

Neste quesito, entende-se por leite cru refrigerado, o produto oriundo da ordenha completa, ininterrupta, em condições de higiene, de vacas sadias, bem alimentadas e descansadas, mantido nas temperaturas de $4^{\circ} \mathrm{C}$ na propriedade leiteira/tanque comunitário e de $7^{\circ} \mathrm{C}$ no estabelecimento processador, transportado em carro tanque isotérmico da propriedade rural para um posto de refrigeração de leite ou estabelecimento industrial adequado, para ser processado (Brasil, 2020).

Uma vez que não há como melhorar a qualidade do leite por meio de processos industriais, a forma de garantir o fornecimento de um produto seguro ao consumidor é o controle das condições de produção, conservação e transporte do leite cru, antes de chegar à indústria (Langoni et al., 2011). A inflamação da glândula mamária é denominada mastite, que pode ser provocada por traumas mecânicos e também inúmeros agentes infecciosos conhecida como Contagem de Células Somáticas no leite - CCS (Langoni, 1999).

Essa infecção afeta a integridade do leite em todos os rebanhos leiteiros. E o controle da mastite tem-se baseado nas boas práticas de ordenha, no tratamento de vacas secas com antibióticos de escolha.

A infecção da glândula mamária é considerada o principal fator que leva ao aumento da celularidade do leite (Pyörälä, 2003; Cunha et al., 2008; Della Libera et al., 2011). A CCS determina todos os tipos celulares presentes no leite, não fazendo a diferenciação entre os distintos tipos celulares, que incluem as células epiteliais, os linfócitos, os macrófagos e os neutrófilos (Koess e Hamann, 2008).

A Instrução Normativa No 76 de 26 de novembro de 2018 torna obrigatória a análise do leite cru refrigerado, pela Rede Brasileira de Laboratórios de Controle de Qualidade do Leite (RBQL) e o leite cru refrigerado de tanque individual ou de uso comunitário deve apresentar médias geométricas trimestrais de Contagem de Células Somáticas de no máximo 500.000 $\mathrm{CS} / \mathrm{mL}$ (quinhentas mil células por mililitro). A partir de então, os estabelecimentos, tanques coletivos e produtores individuais foram obrigados a apresentar resultados de contagem de células somáticas de até 5x105 CS/mL.

Os métodos indiretos utilizados para avaliar a contagem celular, foram: O Somaticell® e o Ekomilk scan®. O primeiro é um teste qualitativo, mas apresenta uma conversão para valores quantitativos, oferece um limite de resultados entre 69.000 a 1.970.000 CS/mL (Rodrigues et al., 2009). Já o equipamento Ekomilk scan, possui uma faixa de resultado de 90.000 a 1500.000/ CS/mL, analisa as células somáticas por meio do teste que envolve a adição de uma solução surfactante na amostra de leite, formando um gel viscoso em que é realizada, a CCS por mL de leite. Objetivou-se analisar a confiabilidade dos testes rápidos Somaticell@ e Ekomilk scan ${ }^{\circledR}$ para detecção da contagem de células somáticas em leite cru refrigerado de produtor individual no Piauí.

\section{Metodologia}

As amostras do leite foram obtidas de vinte produtores da localidade rural do município de Caraúbas, PI, escolhidos 
aleatoriamente. O leite foi mantido na temperatura estabelecida pela INSTRUÇÃO NORMATIVA $\mathrm{N}^{\circ} 55$, DE 30 DE SETEMBRO DE 2020, de conservação e expedição do leite no posto de refrigeração como na unidade de beneficiamento de leite: $5,0{ }^{\circ} \mathrm{C}$ (cinco graus Celsius). As amostras foram devidamente acondicionadas em frascos pet estéreis adquiridas no comércio da capital. As amostras foram analisadas no laboratório de Alimentos de Instituto Federal do Piauí - IFPI, onde foram submetidas a dois testes rápidos para contagem estimada de células somáticas no leite ambos da marca Cap-lab utilizando o Kit somaticell modelo somatictest (T1) e o equipamento Ekomilk scan (T2). As análises foram feitas em duplicatas e avaliadas de maneira individual, pela média dos produtores e pelo pool das amostras, onde foram coletadas por sete vezes durante o período de fevereiro a abril de 2014.

A coleta das amostras foi realizada no posto de recebimento de leite do município de Caraúbas-Piauí no momento da entrega do leite de cada produtor ao posto de refrigeração. O leite foi homogeneizado por meio de conchas de aço inoxidável, mergulhando-as no leite, cerca de três vezes. Em seguida, foram transferidos $100 \mathrm{ml}$ do leite para os frascos. As amostras foram encaminhadas ao Laboratório do IFPI em até vinte quatro horas depois de colhidas, e acondicionadas em caixas térmicas contendo gelo reciclável. Após chegada ao laboratório, as amostras foram retiradas da caixa térmica para realização das análises.

Para realização da análise pelo teste Kit somaticell (T1) foram depositados 2 mililitros de leite em tubos apropriados seguido da adição de $2 \mathrm{~mL}$ do reagente. Em seguida, a solução foi agitada por um canudo pelo tempo de 20 segundos com 30 movimentos de sobe e desce. Imediatamente, o tubo graduado foi colocado de cabeça para baixo para escoamento da solução por 30 segundos, voltando o tubo a posição de origem por 5 segundos. A solução remanescente indicou a quantidade de CCS em milhares.

Para o segundo teste Ekomilk scan (T2), as amostras precisavam está com temperaturas entre $20{ }^{\circ} \mathrm{C}$ e $22{ }^{\circ} \mathrm{C}$ assim como os reagentes utilizados. Foram adicionados com auxílio de pipeta de vidro $10 \mathrm{~mL}$ da amostra de leite e $5 \mathrm{~mL}$ do reagente, totalizando $15 \mathrm{~mL}$ da solução. E o resultado foi obtido no visor do equipamento $\mathrm{em}^{\mathrm{cm}}$.

\subsection{Análise estatística}

Adotou-se o delineamento em blocos ao acaso, com dois tratamentos T1 e T2 e sete repetições analisadas em duplicata. Realizou estatística descritiva para médias e desvio padrão, utilizando o PROC MEANS do SAS e aplicou-se teste de médias de Duncan, ao nível de probabilidade 5\%, segundo metodologia recomendada por (Sampaio, 2002), utilizando-se o procedimento para modelos lineares generalizados (PROC GLM) do logiciário estatístico (Sas, 2002).

\section{Resultados e Discussão}

Na Tabela 1 são apresentados os resultados dos dois métodos em estudo em função da variável CCS. Onde se observa que houve diferença estatística entre os tratamentos $(\mathrm{p}<0,01)$. O T1 teve uma contagem de células somáticas superior ao T2.

Tabela 1. Contagem de células somáticas (CCS) em leite cru refrigerado através de dois métodos rápidos analíticos.

\begin{tabular}{llllll}
\hline \multirow{2}{*}{ Variável } & Tratamentos & & P & C \\
\cline { 2 - 3 } & Somaticell (T1) & Ekomilk scan (T2) & \\
\hline \multirow{2}{*}{ CCS x1000 } & $432,56^{\mathrm{a}}$ & $229,22^{\mathrm{b}}$ & & 0,000 & 14, \\
\hline
\end{tabular}

Médias seguidas de letras diferentes diferem entre si pelo teste de Duncan. Fonte: Autores. 
Observou-se na Tabela 1 diferenças estatísticas $(\mathrm{p}=0,0002)$ entre os métodos somaticell e ekomilk scan para contagem de células somáticas em leite cru refrigerado. Apesar de ter sido encontrado diferença entre os métodos, ambos os resultados se encontram -se dentro dos valores legais aceitos pela instrução normativa $\mathrm{n}^{\circ} 76$. Verifica-se que o $\mathrm{T} 2$ foi o que apresentou menor contagem de células somáticas e, portanto, considerado o mais indicado. O Desvio padrão da média foi 37,53, este valor é considerado elevado, devido à existência de um grande número de dados com baixa CCS e um pequeno número de dados com alta CCS, o que pode ser visto na Tabela 2. O valor encontrado no teste somaticell (T1) foi estatisticamente maior e isso pode está associado ao manuseio e interpretação de quem o executa podendo levar a maiores variações dos resultados encontrados.

A Figura 1 abaixo expressa a média dos valores obtidos dos 20 produtores de leite nas diferentes semanas de coleta em que se puderam observar os picos máximos e mínimos dos dois diferentes métodos estudados. Percebe-se que a média do valor máximo para o método somaticell representou 800,43 e o valor mínimo 130,43, já o método ekomilk scan está representado pelos valores máximos e mínimos de 445 e 130,43 respectivamente. A CCS do leite do produtor 09 foi o que se diferenciou em ambas as técnicas empregadas. Para o valor mínimo, o leite do produtor número 04 manteve valor semelhante nos dois métodos. O que demostra concordância no seguimento dos dois testes para o mesmo produtor.

Figura 1. CCS. Médias dos valores de CCS por dois métodos rápidos distintos.

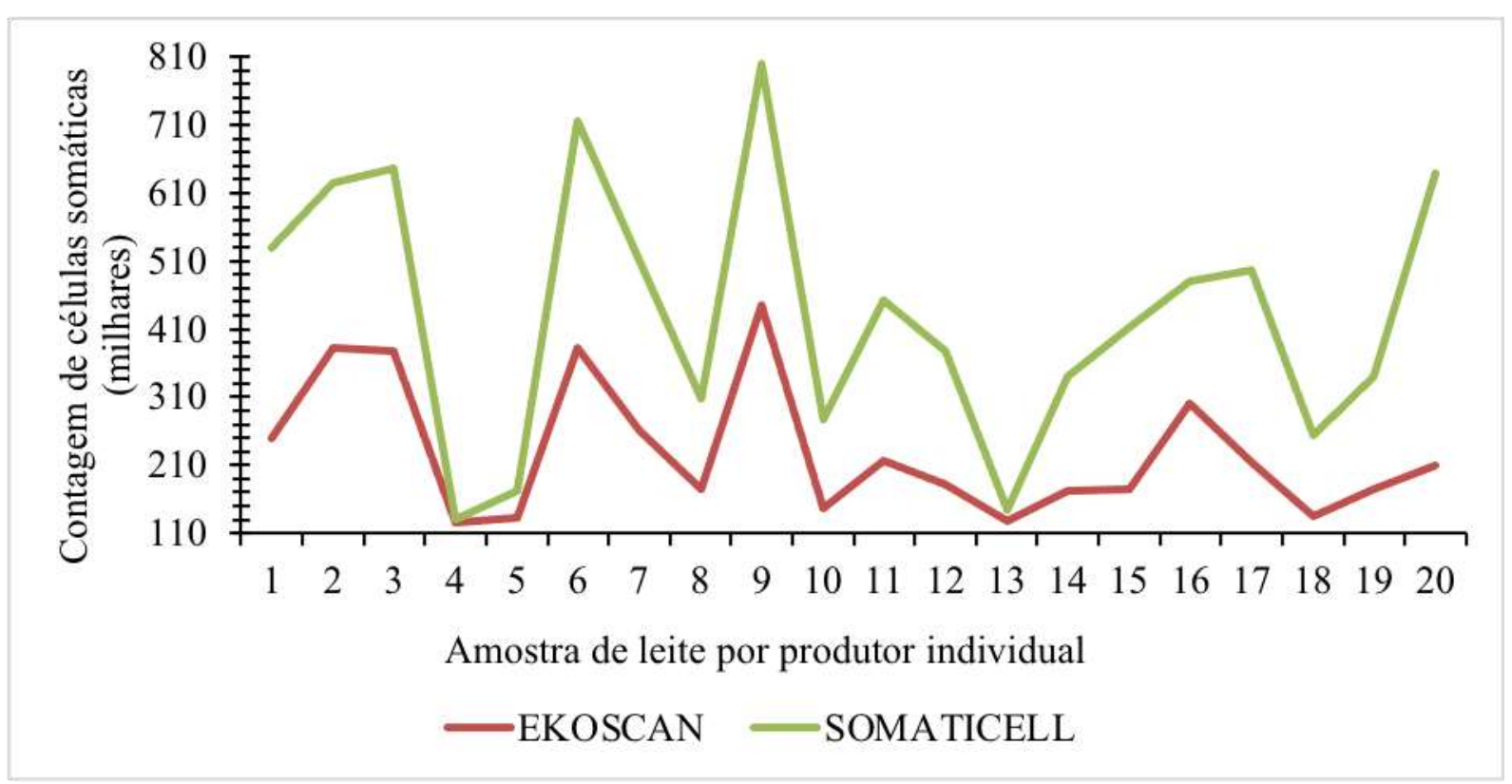

Fonte: Autores. 
Tabela 2. Valores de CCS em leite cru refrigerado de produtores individuais através de dois diferentes métodos analíticos em sete repetições (x $1.000 \mathrm{CS} / \mathrm{mL})$.

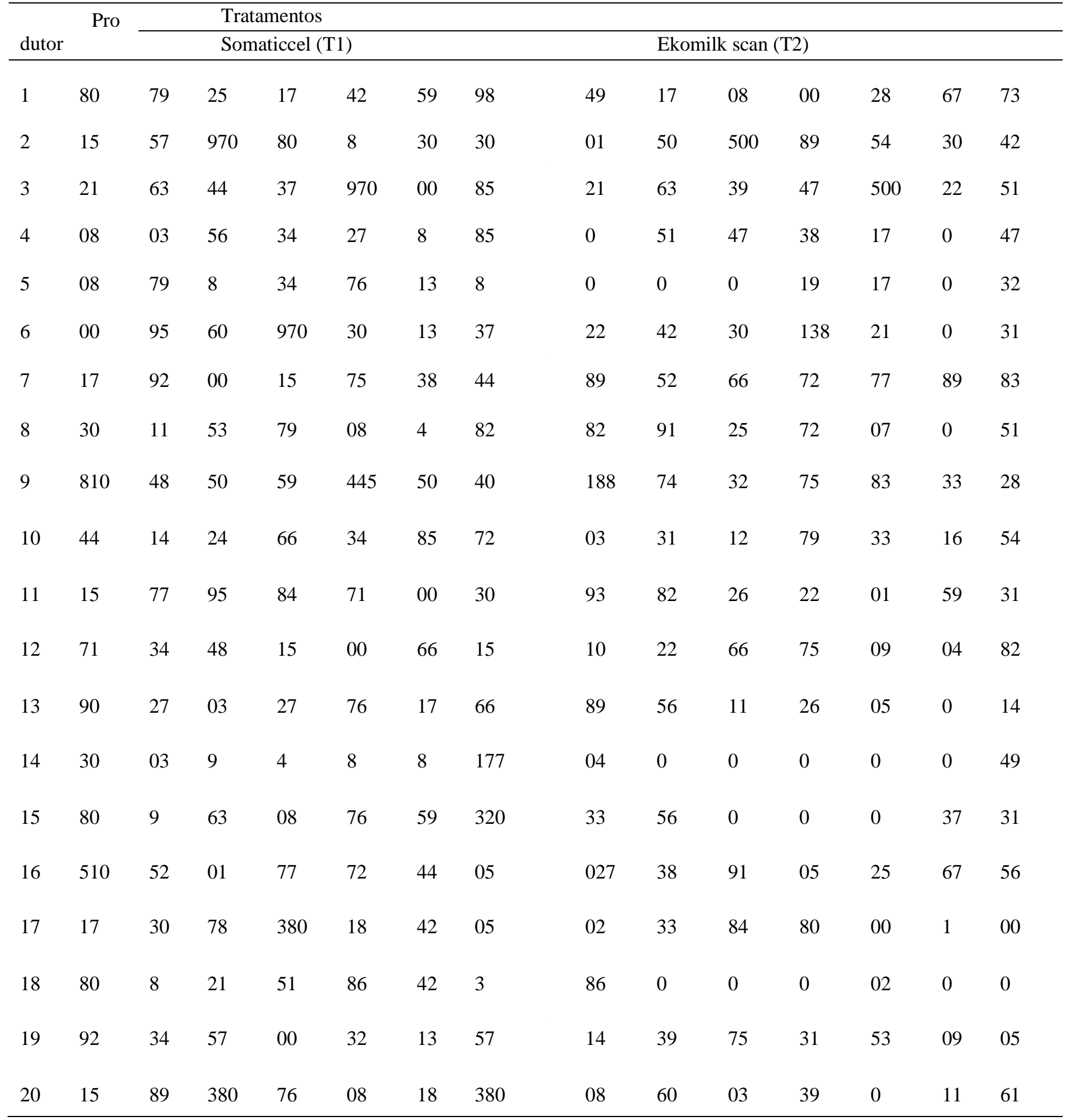

Fonte: Autores.

Há uma necessidade de conhecimento do produtor sobre o processo de obtenção do leite, as quais podem ser assinaladas através da existência de problemas nos processos de higienização de equipamentos, utensílios e ambiente, funcionamento e manutenção dos resfriadores de imersão e manejo da ordenha (Rosa \& Queiroz, 2007).

A Educação continuada entre produtores e laticínios é fundamental para a produção de um leite de qualidade assegurando a sanidade do animal e a saúde do consumidor (Nero et al., 2005). 


\section{Conclusão}

Os Kits somaticell e ekomilk scan utilizados neste trabalho mostraram-se confiáveis para contagem de CCS em leite cru refrigerado. Porém, a técnica aplicada e a confiabilidade de quem o faz, pode influenciar na CCS no leite de vacas. A utilização desses testes como rotina em laboratórios de laticínios pode ser uma alternativa para auxiliar na informação dos resultados de CCS que atualmente são mensais, passando a ter mais dados e gerar conhecimentos afim de investigar as causas da inflamação, contribuindo para o emprego de ações corretivas de forma mais rápida na melhoria e prevenção do problema.

É necessário investigar em trabalhos futuros os fatores infeciosos e não infeciosos responsáveis pela variação entre as técnicas utilizadas. Orientando os proprietários em Boas Práticas de ordenha, de forma a melhorar a sanidade do rebanho e dos seus produtos.

\section{Referências}

Bautista, M. N., Lavilla-Pitogo, C. R., Subosa, P. F., \& Begino, E. T., (1994). Aflatoxin B ${ }_{1}$ contamination of shrimp feeds and its effect on growth and hepatopancreas of pre-adult Penaeus monodon. Journal of Science Food Agriculture, 65 (01), 5-11.

Brasil., (2018). Ministério da Agricultura Pecuária e Abastecimento. Instrução normativa n. 76, de 26 de novembro de 2018 . Aprova Regulamentos Técnicos que fixam a identidade e as características de qualidade que devem apresentar o leite cru refrigerado, o leite pasteurizado e o leite pasteurizado tipo A, na forma desta Instrução Normativa e do Anexo Único. Diário Oficial da União, 30/11/2018 | Edição: 230 | Seção: 1 | Página: 9

Cunha, R. P. L., Molina, L. R., \& Carvalho, A. U., (2008). Mastite subclínica e relação da contagem de células somáticas com número de lactações, produção e composição química do leite em vacas da raça holandesa. Arq. Bras. Med. Vet. Zoot., 60, 19-24.

Della Libera, A. M. M. P., Souza, F. N., Blagitz, M. G., \& Batista, C. F., (2011). Avaliação de indicadores inflamatórios no diagnóstico da mastite bovina. Arq. Inst. Biol., 78, 297-300.

Dürr, J. W., (2004). Programa nacional de melhoria da qualidade do leite: uma oportunidade única. In: O Compromisso com a qualidade do leite no Brasil. Passo Fundo, RS: Editora Passo Fundo, 38-55.

Fernandes, M. A., (2002). Avaliação das características físico-químicas, celulares e microbiológicas do leite de cabras saanen e alpina, criadas no Estado de São Paulo. 2002. 152 F. (Tese de doutorado), Usp.

Fonseca, L. F. L; \& Santos, M. V., (2000). Qualidade do leite e controle de mastite. Lemos Editorial, 175p.

Gomes, V., \& Della Libera, A. M. M. P. (2004). Influência do estágio de lactação na composição do leite de cabras (Capra Hircus). Braz. J. Vet. Res. Anim. Sci., 41, 339-342.

Koess, C., \& Hamann, J., (2008). Detection of mastitis in the bovine mammary gland by flow cytometry at early stages. J. Dairy Res., 75, $225-232$.

Langoni, H., (2011). Aspectos microbiológicos e de qualidade do leite bovino. Pesquisa Veterinária Brasileira, 31 (12), $1059-1065$.

Langoni, H., (1999). Complexidade etiológica da mastite bovina. In: Encontro de pesquisadores em mastites, 1999, Botucatu. Anais... Botucatu: Faculdade de Medicina Veterinária e Zootecnia, 3-18.

Lima, M. C. G., Sena, M. J.; \& Mota, R. A., (2006). Contagem de células somáticas e análises físico-químicas e microbiológicas do leite cru tipo c produzido na Região Agreste do Estado de Pernambuco. Arq. Inst. Bio. 73, 89-95.

Mcdougall, S., \& Voermans. (2002). M. Influence of estrus on somatic cell count in dairy goats. J. Dairy Sci. 85, 378-383.

Nero, L. A., Mattos, M. R., \& Beloti, V., (2005). Leite cru de quatro regiões leiteiras brasileiras: perspectivas de atendimento dos requisitos microbiológicos estabelecidos pela Instrução Normativa 51. Cienc. Tecnol. Aliment, 25, 191-195.

Pyöralä, S., (2003). Indicators of inflammation in the diagnosis of mastitis. Vet. Res., 34, 565-578.

Rodrigues, A. C. O., Cassoli, L. D., \& Machado, P. F. (2009). Evaluation of an on-farm test to estimate somatic cell count. J. Dair. Scienc, 92 , $990-995$.

Rosa, L. S., \& Queiroz, M. I. (2007). Avaliação da qualidade do leite cru e resfriado mediante a aplicação de princípios do APPCC. Cienc. Tecnol. Aliment, $27,422-430$.

Sampaio, I. B. M. (2002). Estatística aplicada à experimentação animal. Fundação de Ensino e Pesquisa em Medicina Veterinária e Zootecnia, 265.

Santos, M. V., \& Fonseca, L. F. L. (2007). Estratégias para controle de mastite e melhoria da qualidade do leite. Manole. 314.

Statistical Analysis System. Sas/Stat user's guide. Version 8.0. Cary, 2002. 5. 